\title{
Experience of Laparoscopic Cholecystectomies in a Tertiary Care Hospital: a Retrospective Study
}

\author{
Aamir Hussain Hela* (D), Haseeb Mohammad Khandwaw (iD, Rahul Kumar, Mir Adnan Samad (iD
}

\begin{abstract}
Introduction: Laparoscopic cholecystectomy is the most commonly performed surgical procedure of digestive tract. It has replaced open cholecystectomy as gold standard treatment for cholelithiasis and inflammation of gallbladder. It is estimated that approximately $90 \%$ of cholecystectomies in the United States are performed using a laparoscopic approach. The aim of this study was to evaluate the outcome of laparoscopic cholecystectomy in context to its complications, morbidity and mortality in a tertiary care hospital.

Methods: This retrospective study was conducted on 1200 patients, who underwent laparoscopic cholecystectomies, during the period from January 2019 to December 2019, at Government Medical College Jammu J \& K, India and necessary data was collected and reviewed.

Results: In our study, a total of 1200 patients were studied including 216 males (18\%) and 984 females (82\%). The mean age of the patients was $43.35 \pm 8.61$. The mean operative time in our study was $55.5 \pm 10.60$ minutes with range of $45-90$ minutes. Conversion rate was $2.6 \%$. 2 patients were re-explored. Bile duct injury was found in 6 patients $(0.5 \%)$.

Conclusions: Gallstone disease is a global health problem. Laparoscopic cholecystectomy has now replaced open cholecystectomy as the first choice of treatment for gallstones. Gall stone diseases is most frequently encountered in female population. The risk factors for conversion to open cholecystectomy include male gender, previous abdominal surgery, acute cholecystitis, dense adhesions and fibrosis in Calot's triangle, anatomical variations, advanced age, comorbidity, obesity, suspicion of common bile duct stones, jaundice, and decreased surgeon experience. The incidence of surgical site infection has significantly decreased in laparoscopic cholecystectomy compared to open cholecystectomy. In our study we could not find any case of surgical site infection.
\end{abstract}

\section{Keywords}

Cholecystectomy; Laparoscopic Cholecystectomy; Experience with Laparoscopic Cholecystectomy; Complications Associated with Cholecystectomy

Department of Surgery, Government Medical College Jammu, India

*Corresponding author: aamir345679@gmail.com

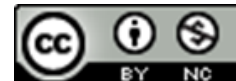

Copyright @Aamir Hussain Hela, Haseeb Mohammad Khandwaw, Rahul Kumar, Mir Adnan Samad, 2020

\section{Introduction}

Laparoscopic cholecystectomy is the most commonly performed surgical procedure of digestive tract [1]. It has replaced open cholecystectomy as gold standard treatment for cholelithiasis and inflammation of gall bladder [2]. The first laparoscopic cholecystectomy was performed in 1987 by Mouret. The surgeons are performing increasing number of laparoscopic cholecystectomies because of accompanying less postoperative pain, shorter hospital stay, faster recovery, improved cosmetic results, early return to work, fewer complications such as infection [3], adhesions, short operating time and low learning curve [4] and, it is superior to other developed techniques because of economic advantage [5]. The main risk associated with the laparoscopic cholecystectomy appears to be a higher incidence of bile duct injury than open cholecystectomy 0.3-0.8\% [6].

Currently, it is estimated that approximately $90 \%$ of cholecystectomies in the United States are performed using a laparoscopic approach [7]. There has been an increase in the rate of cholecystectomies subsequent to the introduction of laparoscopic cholecystectomy accompanied by evidence of lower clinical thresholds for operative therapy of gallbladder 
disease $[8,9]$.

The aim of this study was to evaluate the outcome of laparoscopic cholecystectomy in context to its complications, morbidity and mortality in a tertiary care hospital.

\section{Materials and Methods}

This retrospective study was conducted on 1200 patients, who underwent laparoscopic cholecystectomies, during the period from January 2019 to December 2019, at Government Medical College Jammu J \& K, India.

The following data was retrospectively reviewed; patient's demographics (age, gender), preoperative investigations (routine in all patients $\mathrm{CBC}$, bleeding-coagulation times, liver function tests, renal function tests, blood glucose level, screening for hepatitis), systemic diseases (diabetes mellitus, hypertension, respiratory and cardiac problems). American Society of Anaesthesiologist's (ASA) score, intra-operative findings (duration of operation, intra-operative bleeding and iatrogenic injuries), conversion from laparoscopic to open cholecystectomy and reason for conversion, postoperative complications, early (haemorrhage, bile leak, wound infection) and late complications (biliary stricture and port site hernia), hospital stay and mortality were reviewed from patients' records. Patients having incomplete data on their files were not included in the study.

Ultrasonography was routinely performed on all patients to confirm the clinical diagnosis of cholelithiasis with number of stones, sizes, gall-bladder wall thickness, pericholecystic collection, and diameter of common bile duct.

Laparoscopic cholecystectomies were performed using the standard four port technique. After surgery, patients were managed for three months.

\section{Ethical Statement}

The protocol of the study was approved by the local ethical committee (Government Medical College Jammu J \& K, India).

\section{Results}

In our study, a total of 1200 patients were studied including 216 males (18\%) and 984 females (82\%). The female to male ratio was 9:2. Most of the patients were in age group of 4050years $(36 \%)$ followed by $30-40$-year age group (26\%). The mean age of the patients was $43.35 \pm 8.61$ (Table 1 ).

History of previous abdominal surgery was found in 132 patients (11\%). History of hypertension was found in $230(19.1 \%)$ patients, Diabetes Mellitus in $144(12 \%)$, ischaemic heart diseases in $36(3 \%)$ and respiratory diseases in $96(8 \%)$ patients.

The pre-operative ultrasonography was showing single calculi in gallbladder in $301(25.08 \%)$ patients and multiple calculi in $886(73.8 \%)$ patients. $13(1.08 \%)$ patients were showing gallbladder polyps.
Table 1. Age distribution.

\begin{tabular}{c|cc}
\hline Age group (in years) & Frequency & Percentage \\
\hline $10-20$ & 12 & 1 \\
$20-30$ & 108 & 9 \\
$30-40$ & 312 & 26 \\
$40-50$ & 432 & 36 \\
$50-60$ & 300 & 25 \\
$60-70$ & 36 & 3 \\
\hline Total & 1200 & 100 \\
\hline
\end{tabular}

According to the American Society of Anaesthesiologists' (ASA) classification, $348(29 \%)$ patients were ASA I, $768(64 \%)$ were ASA II, and $84(7 \%)$ were ASA III.

The mean operative time in our study was $55.5 \pm 10.60 \mathrm{~min}$ utes with range of $45-90$ minutes.

In our study laparoscopic cholecystectomy was converted to open in 32 patients $(2.6 \%)$. The cause of conversion was presence of cholecystoenteric fistula in 8 patients, difficult dissection owing to presence of severe inflammation in 7 patients, obscured anatomy in 12 patients, excessive bleeding in 2 patients and biliary injury in 3 patients. Drains were placed in $480(40 \%)$ patients.

2 patients were re-explored. One patient was explored in view of post op bleeding. He developed hypotension, tachycardia and pallor. Drain had been placed intraoperatively but it had got blocked and was not draining. Patient was re explored 14 hours after surgery. Bleeding from cystic artery stump was found and secured and patient did well in post op period. Second patient developed biliary peritonitis on $3^{\text {rd }}$ post-operative day and was explored on same day and found to have cystic stump leak.

Bile duct injury was found in 6 patients $(0.5 \%)$. Injury was detected intra operatively in 3 patients and procedure was converted to open one. In all three there was a tear in CBD which was repaired primarily over a $\mathrm{T}$ tube. In 3 patients, injury was detected in immediate post-operative period. One of them was managed conservatively and leak stopped in 12 days. Two patients were presented with Bilioma and were drained percutaneously. In our study there was no case of bowel or major vascular injury.

In our study, we encountered $42.66 \%$ of the patient with clear anatomy at Calot's triangle while in $18.5 \%$ of the cases it was not clear and $8.41 \%$ had adhesions at Calot's triangle (Table 2).

The mean hospital stay of patients in our study was $1.6 \pm 0.9$ days with range of 12 hours to 14 days. In our study, no patient developed wound infection and during the period of follow up, no patient developed biliary stricture or port site hernia.

\section{Discussion}

Gallstone disease is a global health problem. The incidence is $10-20 \%$ of the whole adult population. Laparoscopic chole- 
Table 2. Intra operative findings.

\begin{tabular}{l|cc}
\hline IOF & Frequency & Percentage \\
\hline Contracted GB & 43 & 3.58 \\
Mucocele & 61 & 5.08 \\
Empyema & 73 & 6.08 \\
Mirrizi type 1 & 16 & 1.33 \\
Anterior RHA & 26 & 2.16 \\
Short cystic duct & 92 & 7.66 \\
Intra hepatic GB & 53 & 4.41 \\
Bilobed GB & 1 & 0.08 \\
\hline
\end{tabular}

cystectomy has now replaced open cholecystectomy as the first choice of treatment for gallstones. Laparoscopic cholecystectomy is performed in over $90 \%$ of elective cholecystectomies making it one of the most frequently performed operations in the world [10]. Laparoscopic cholecystectomy causes less pain after surgery, shorter hospital stay, faster return to work activities and a lower metabolic-endocrineimmune response to trauma [11]. This procedure has been the gold standard for elective cholecystectomy for the general population in the last two decades [12].

Gall stone disease is most frequently encountered in female population and this was seen in our study with female to male ratio of 9:2. The mean age of the patients was $43.35 \pm 8.61$.

The risk factors for conversion to open cholecystectomy include male gender, previous abdominal surgery, acute cholecystitis, dense adhesions and fibrosis in Calot's triangle, anatomical variations, advanced age, comorbidity, obesity, suspicion of common bile duct stones, jaundice, and decreased surgeon experience [13]. The incidence of rate of conversion from laparoscopic to open cholecystectomy varies from 2.6 to $7.7 \%$ [14]. In our study rate of conversion was $2.6 \%$ with obscured anatomy and presence of cholecystoenteric fistula being the most common reasons for conversion.

The major vascular injury is the $2^{\text {nd }}$ most common cause of death in patients undergoing laparoscopic cholecystectomy. The incidence of major vascular injury is around $0.03-0.06 \%$. In our study no case of major vascular injury was found. However, 2 cases were converted to open surgeries due to excessive bleeding from gallbladder bed and one patient was re-explored in view of excessive bleeding from cystic duct stump.

Abdominal drain was placed in $40 \%$ of patients with intraoperative bleeding or had biliary contamination from gallbladder due to incidental perforation during dissection.

Biliary injury continues to be a major complication following laparoscopic cholecystectomy. In the era of laparoscopic cholecystectomy incidence of bile duct injuries has increased to $0.8 \%$ whilst the one related to the open route remained between $0.2-0.3 \%$ [15]. In our study incidence of bile duct injury was $0.5 \%$ with $50 \%$ of them being detected intraoperatively and $50 \%$ in post-operative period. One patient needed
ERCP and stenting and two patients presented with Bilioma which was drained percutaneously.

The incidence of surgical site infection has significantly decreased in laparoscopic cholecystectomy compared to open cholecystectomy $[2,16]$. In our study we could not find any case of surgical site infection.

\section{Conclusion}

Cholecystectomy remains one of the most common operations performed in the world. Laparoscopic cholecystectomy is currently the standard for treatment of gallstone and gallbladder disease. There are numerous advantages of laparoscopic cholecystectomy over open cholecystectomy, including decreased pain, length of hospital stay, recovery time, and incisional complications, and improved cosmesis. However, occasionally anatomic or physiologic considerations will hinder or preclude the minimal access approach, and conversion to an open operation in such cases reflects sound clinical judgment and should not be considered a complication. The goal of any cholecystectomy, whether laparoscopic or open, is the safe removal of the gallbladder while avoiding injury to the CBD at all costs.

\section{Conflict of Interest}

The authors declare that no conflicts exist.

\section{Financial Disclosure}

The authors declared no financial support.

\section{References}

[1] Karimian F, Aminian A, Mirsharifi R, Mehrkhani F. Surgical options in the management of cystic duct avulsion during laparoscopic cholecystectomy. Patient Saf Surg [Internet]. 2008;2(1):17. Available from: https://doi.org/10.1186/1754-9493-2-17 [PMid:18565237 PMCid:PMC2442050]

[2] Duman K, Sezer K, Yilmaz F, Akin M. The clinical outcome of traditional laparoscopic cholecystectomy. Gaziantep Med J [Internet]. 2013;19(1):35-39. Available from: https://doi.org/10.5455/GMJ-30-2012-118

[3] Passos MA, Portari-Filho PE. Antibiotic prophylaxis in laparoscopic cholecistectomy: is it worth doing? ABCD Arq Bras Cir Dig (São Paulo) [Internet]. 2016 Sep;29(3):170-172. Available from: https://doi.org/10.1590/0102-6720201600030010 [PMid:27759780 PMCid:PMC5074668]

[4] Ivatury SJ, Louden CL, Schwesinger WH. Contributing Factors to Postoperative Length of Stay in Laparoscopic Cholecystectomy. JSLS J Soc Laparoendosc Surg [Internet]. 2011 Sep;15(2):174-178. Available from: 
https://doi.org/10.4293/108680811X13022985132254 [PMid:21902970 PMCid:PMC3148866]

[5] Nuzzo G, Giuliante F, Giovannini I, Ardito F, D’Acapito F, Vellone M, et al. Bile Duct Injury During Laparoscopic Cholecystectomy. Arch Surg [Internet]. 2005 Oct 1;140(10):986-992. Available from: $\quad$ https://doi.org/10.1001/archsurg.140.10.986 [PMid:16230550]

[6] Kreimer F, Cunha DJ, Ferreira CCG, Rodrigues TM, Fulco LG de M, Godoy ESN. Comparative analysis of preoperative ultrasonography reports with intraoperative surgical findings in cholelithiasis. ABCD Arq Bras Cir Dig (São Paulo). 2016 Mar 1;29(1):26-29. Available from: https://doi.org/10.1590/0102-6720201600010007 [PMid:27120735 PMCid:PMC4851146]

[7] Ingraham AM, Cohen ME, Ko CY, Hall BL. A Current Profile and Assessment of North American Cholecystectomy: Results from the American College of Surgeons National Surgical Quality Improvement Program. J Am Coll Surg [Internet]. 2010 Aug 1;211(2):176-186. Available from: https://doi.org/10.1016/j.jamcollsurg.2010.04.003 [PMid:20670855]

[8] Escarce JJ. Falling Cholecystectomy Thresholds Since the Introduction of Laparoscopic Cholecystectomy. JAMA J Am Med Assoc [Internet]. 1995 May 24;273(20):1581-1585. Available from: https://doi.org/10.1001/jama.1995.03520440035033 [PMid:7745770]

[9] Legorreta AP. Increased Cholecystectomy Rate After the Introduction of Laparoscopic Cholecystectomy. JAMA J Am Med Assoc. 1993 Sep 22;270(12):1429-1432. Available from: https://doi.org/10.1001/jama.1993.03510120051029 [PMid:8371441]

[10] Sheffield KM, Ramos KE, Djukom CD, Jimenez CJ, Mileski WJ, Kimbrough TD, et al. Implementation of a Critical Pathway for Complicated Gallstone Disease: Translation of Population-Based Data into Clinical Practice. J Am Coll Surg [Internet]. 2011 May 22;212(5):835-843. Available from: https://doi.org/10.1016/j.jamcollsurg.2010.12.047 [PMid:21398156 PMCid:PMC3350377]

[11] Alponat A, Kum CK, Koh BC, Rajnakova A, Goh PMY. Predictive Factors for Conversion of Laparoscopic Cholecystectomy. World J Surg [Internet]. 1997 Jul 22;21(6):629-633. Available from: https://doi.org/10.1007/PL00012288 [PMid:9230661]

[12] Dubois F, Berthelot G, Levard H. Coelioscopic cholecystectomy: Experience with 2006 cases. World J Surg [Internet]. 1995 Jul 22;19(5):748-752. Available from: https://doi.org/10.1007/BF00295921 [PMid:7571675]

[13] Duncan CB, Riall TS. Evidence-Based Current Surgical Practice: Calculous Gallbladder Disease. J Gastrointest Surg [Internet]. 2012 Nov 18;16(11):2011-2025. Available from: https://doi.org/10.1007/s11605-012-2024-1 [PMid:22986769 PMCid:PMC3496004]

[14] Ballal M, David G, Willmott S, Corless DJ, Deakin M, Slavin JP. Conversion after laparoscopic cholecystectomy in England. Surg Endosc [Internet]. 2009 Oct 6;23(10):2338-2344. Available from: https://doi.org/10.1007/s00464-009-0338-1 [PMid:19266237]

[15] Wu YV, Linehan DC. Bile Duct Injuries in the Era of Laparoscopic Cholecystectomies. Surg Clin North Am [Internet]. 2010 Aug 6;90(4):787-802. Available from: https://doi.org/10.1016/j.suc.2010.04.019 [PMid:20637948]

[16] Varela JE, Wilson SE, Nguyen NT. Laparoscopic surgery significantly reduces surgical-site infections compared with open surgery. Surg Endosc [Internet]. 2010 Feb 17;24(2):270-276. Available from: https://doi.org/10.1007/s00464-009-0569-1 [PMid:19533235]

Received: 2020-04-29

Revised: $2020-06-05$

Accepted: 2020-10-01 